\title{
NÍVEL DE ATIVIDADE, INFLAÇÃO E POLÍTICA MONETÁRIA
}

\section{A evolução dos principais indicadores econômicos do Brasil em 2007}

\section{Introdução}

\section{Guilherme R. S. Soura e Silwa*} Lucas Lautert Deardi **

Este artigo pretende apresentar e discutir os indicadores de cinco pontos da economia brasileira. Inicialmente, pretende-se mostrar o desempenho recente dos principais índices da inflação brasileira e suas perspectivas. Em seguida, faremos uma análise da atividade produtiva a nível agregado, do comércio internacional e do mercado de trabalho. E, por último, uma visão da condução da política monetária será apresentada.

As previsões econômicas fornecidas foram coletadas a partir dos dados disponibilizados pelo Banco Central do Brasil em seu Departamento Gerin (GerênciaExecutiva de Relacionamento com Investidores). A Gerin foi criada em abril de 1999, como parte do arcabouço do regime monetário de metas para a inflação. Seu objetivo é monitorar a evolução do consenso de mercado para as principais variáveis macroeconômicas de forma a gerar subsídios para a implementação da política monetária. Atualmente, a pesquisa acompanha as expectativas de mercado para diferentes índices de preços, crescimento do PIB e da produção industrial, taxa de câmbio, taxa Selic, variáveis fiscais e indicadores do setor externo ${ }^{14}$.

\section{Inflação atual e perspectivas}

Os dados recentes da inflação brasileira têm demonstrado um aumento nos principais índices de preços. A tabela 1 destaca as variações mensais, acumuladas no ano de 2007 e acumuladas nos últimos 12 meses dos seguintes indicadores: Índice Geral de Preços do Mercado (IGP-M); Índice Geral de Preços - Disponibilidade Interna (IGP-DI); Índice Nacional de Custo da Construção (INCC); Índice de Preço por Atacado -Disponibilidade Interna (IPA-DI); e o Índice Nacional de Preços ao Consumidor Amplo (IPCA).

Nos últimos três meses, de acordo com a tabela 1, os principais indicadores inflacionários vêm apresentando uma elevação, com destaque para o mês de agosto. Os

\footnotetext{
* Mestrando em Desenvolvimento Econômico pela Universidade Federal do Paraná. Endereço eletrônico: guilherme.fdg@uol.com.br

** Professor da FAE Business School e Doutorando em Desenvolvimento Econômico pela Universidade Federal

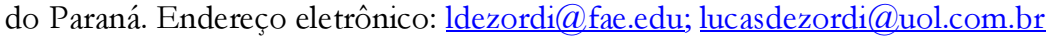

${ }^{14}$ Ver em especial o site: www.bcb.gov.br/expectativa.
} 
índices de preços com as maiores altas nos últimos 12 meses são o IPA-DI e o IGP-DI, com valores de 5,48\% e 5,19\%, respectivamente. O IPCA, índice de preços oficial do regime de metas de inflação, acumulado em 12 meses, está em 4,18\%, isto é, abaixo da meta central para o corrente ano de 4,5\%. O IPCA apresentou nos últimos 8 meses uma variação positiva de $2,80 \%$.

É importante destacar que no acumulado em 12 meses os índices de preços vêm apresentando uma convergência entre 4,5 a $5 \%$ ao ano.

O gráfico 1 ilustra bem esta convergência, descrevendo o comportamento de três índices de inflação: IGP-M; IPA-DI e IPCA entre o período de janeiro de 2006 a agosto de 2007, no acumulado em 12 meses (anualizado). Destaca-se que o IPA-DI por ser sensível às variações cambiais apresentou uma maior oscilação no período. Contudo, com a estabilidade dos níveis de preços observa-se um grande grau de convergência dos indicadores.

Tabela 1. Variação percentual dos principais índices de inflação brasileira

\begin{tabular}{cccccc}
\hline Índices de & \multicolumn{3}{c}{2007} & Acumulado em & Acumulado em \\
Inflação & Junho & Julho & Agosto & 2007 & 12 meses \\
\hline IGP-M & $0,26 \%$ & $0,28 \%$ & $0,98 \%$ & $2,74 \%$ & $4,63 \%$ \\
IGP-DI & $0,26 \%$ & $0,37 \%$ & $1,39 \%$ & $3,24 \%$ & $5,19 \%$ \\
INCC & $0,92 \%$ & $0,31 \%$ & $0,26 \%$ & $4,10 \%$ & $5,05 \%$ \\
IPA-DI & $0,09 \%$ & $0,42 \%$ & $1,96 \%$ & $3,10 \%$ & $5,48 \%$ \\
IPCA & $0,28 \%$ & $0,24 \%$ & $0,47 \%$ & $2,80 \%$ & $4,18 \%$ \\
\hline
\end{tabular}

Fonte: Banco Central do Brasil

Gráfico 1. Desempenho anualizado dos principais índices de preços

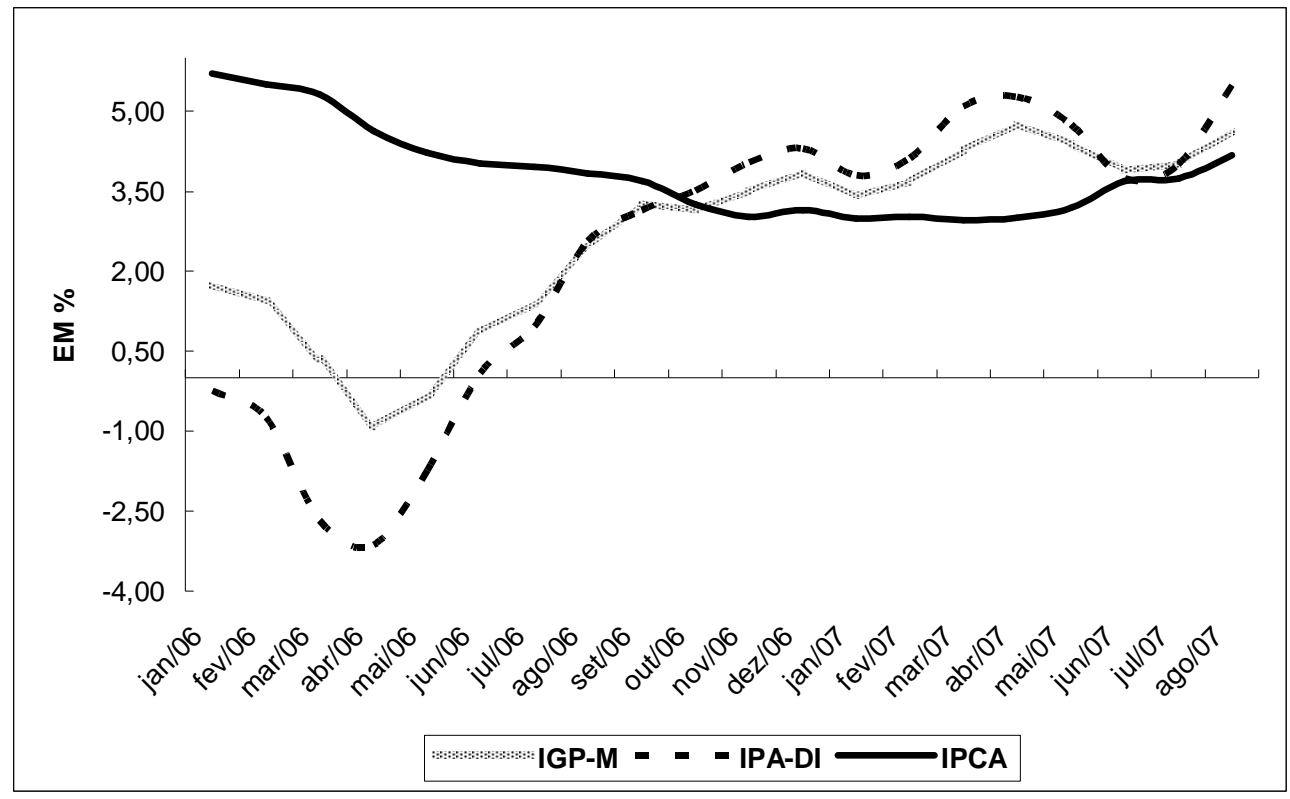

Fonte: Banco Central do Brasil 
A tabela 2 descreve as expectativas de inflação, da Gerin, para os anos de 2007 a 2011. É importante ressaltar que a expectativa do IPCA para os próximos 2 anos está ancorada na meta de 4,5\% estipulada pelo Conselho Monetário Nacional (CMN). Com o crescimento recente da inflação brasileira é muito provável que os agentes econômicos aumentem suas expectativas de inflação no decorrer dos próximos meses. É importante analisar cuidadosamente o comportamento mensal da inflação para os próximos três meses, para se ter uma visão clara do crescimento da oferta e demanda agregada da economia.

Tabela 2. Expectativa média de inflação do mercado - 2006 a 2010

\begin{tabular}{cccccc} 
ANO & IGP-M & IGP-DI & INCC & IPA-DI & IPCA \\
\hline 2007 & $4,33 \%$ & $4,78 \%$ & ND & $4,69 \%$ & $3,94 \%$ \\
2008 & $4,00 \%$ & $4,00 \%$ & ND & $4,23 \%$ & $4,02 \%$ \\
2009 & $4,00 \%$ & $4,00 \%$ & ND & $4,17 \%$ & $4,02 \%$ \\
2010 & $4,00 \%$ & $4,00 \%$ & ND & $4,21 \%$ & $3,99 \%$ \\
2011 & $4,00 \%$ & $4,00 \%$ & ND & $4,01 \%$ & $3,95 \%$ \\
\hline
\end{tabular}

Fonte: Banco Central do Brasil (Gerin)

\section{Nível de atividade}

O IBGE divulgou recentemente os dados relativos ao Produto Interno Bruto (PIB) da economia brasileira, mostrando que no primeiro semestre de 2007, o PIB apresentou crescimento de 4,9\% em relação a igual período de 2006 . Em relação às expectativas de mercado, a tabela 3 apresenta os dados para o crescimento do PIB por setor até o final do ano de 2007, conforme fornecido pela Gerin. Comparando as expectativas de crescimento do PIB do dia 06/09/2007 com as apresentadas no número anterior do boletim Economia é Tecnologia, de 15/06/2007, observamos que há um maior otimismo em relação à taxa de crescimento da economia que passou de 4,28\% para 4,73\%. Cabe destacar que a agropecuária continua sendo o setor com maior perspectiva de crescimento, tanto para 2007 quanto para 2008. O setor de serviços, componente de maior peso no PIB, continua tendo o menor crescimento esperado para 2007 e 2008.

Tabela 3. Expectativas de mercado para o crescimento do PIB por setor

\begin{tabular}{lcc}
\hline \multirow{2}{*}{ Setor } & \multicolumn{2}{c}{ Expectativas variação do PIB (\%) } \\
\cline { 2 - 3 } & 2007 & 2008 \\
\hline Total & 4,73 & 4,36 \\
Agropecuária & 4,86 & 4,78 \\
Indústria & 4,48 & 4,58 \\
Serviços & 4,42 & 4,2 \\
\hline \multicolumn{2}{c}{ Fonte: Banco Central do Brasil (Gerin) $06 / 09 / 2007$}
\end{tabular}


A tabela 4 apresenta os indicadores da indústria brasileira segundo a categoria de uso. $\mathrm{Na}$ passagem de junho para julho do corrente ano houve uma retração no ritmo de produção industrial geral de $0,4 \%$. A indústria de bens de consumo semiduráveis e nãoduráveis foi a que apresentou a maior redução, de 3,3\%. O único setor da indústria que apresentou crescimento nesse período foi o de bens de consumo duráveis, com expansão de $0,8 \%$. No entanto, quando observamos a variação entre a produção de julho de 2006 e julho de 2007, todos os setores apresentam expansão, com destaque para o setor de bens de capital, que cresceu 19\%. Na comparação entre o acumulado do ano de 2007 com o mesmo período do ano anterior o setor de bens de capital também se destaca, apresentando uma expansão de 17\%. A partir desses dados fica evidente que a indústria brasileira vem se preparando para aumentar a sua capacidade produtiva, intensificando a produção de bens de capital.

Tabela 4. Indicadores conjunturais da Indústria segundo categoria de uso - julho/07

\begin{tabular}{lcccc}
\hline & \multicolumn{4}{c}{ Variação (\%) } \\
\cline { 2 - 5 } Categorias de Uso & Jun-07/Jul-07* & Jul-06/Jul-07 & Acumulado no ano & Acumulado 12 meses \\
\hline Bens de Capital & $-1,3$ & 19 & 17 & 12,3 \\
Bens Intermediários & $-0,2$ & 4,7 & 4,2 & 3,4 \\
Bens de Consumo & $-0,9$ & 6,3 & 3,7 & 3,4 \\
$\quad$ Duráveis & 0,8 & 15,1 & 5,9 & 5,4 \\
$\quad$ Semiduráveis e não & & & & 2,8 \\
Duráveis & $-3,3$ & 3,8 & 3 & 4,2 \\
Indústria Geral & $-0,4$ & 6,8 & 5,1 & . \\
\hline
\end{tabular}

Fonte: IBGE, Diretoria de Pesquisas, Coordenação de Indústria

(*) Com ajuste sazonal

O gráfico 2 apresenta o índice de produção industrial geral e o nível de utilização da capacidade instalada na indústria. De acordo com o gráfico, observamos que a produção industrial vem apresentando tendência de crescimento no ano de 2007. No entanto, esta tendência de crescimento não está pressionando o nível de utilização da capacidade instalada, que vem se mantendo abaixo de $83 \%$ nos últimos meses. Isso acontece porque, conforme mostra a tabela 4, a produção de bens de capital vem crescendo substancialmente, expandindo dessa forma a capacidade de produção industrial. Nesse sentido, a economia brasileira atualmente tem espaço para aumentar sua produção industrial, em caso de aumento de demanda, sem que exista o risco imediato de que a capacidade máxima de oferta seja atingida. Assim, é possível um aumento controlado de demanda por produtos industriais sem a ocorrência imediata de pressões inflacionárias. 


\section{Gráfico 2. Produção Industrial Geral e Utilização da Capacidade Instalada}

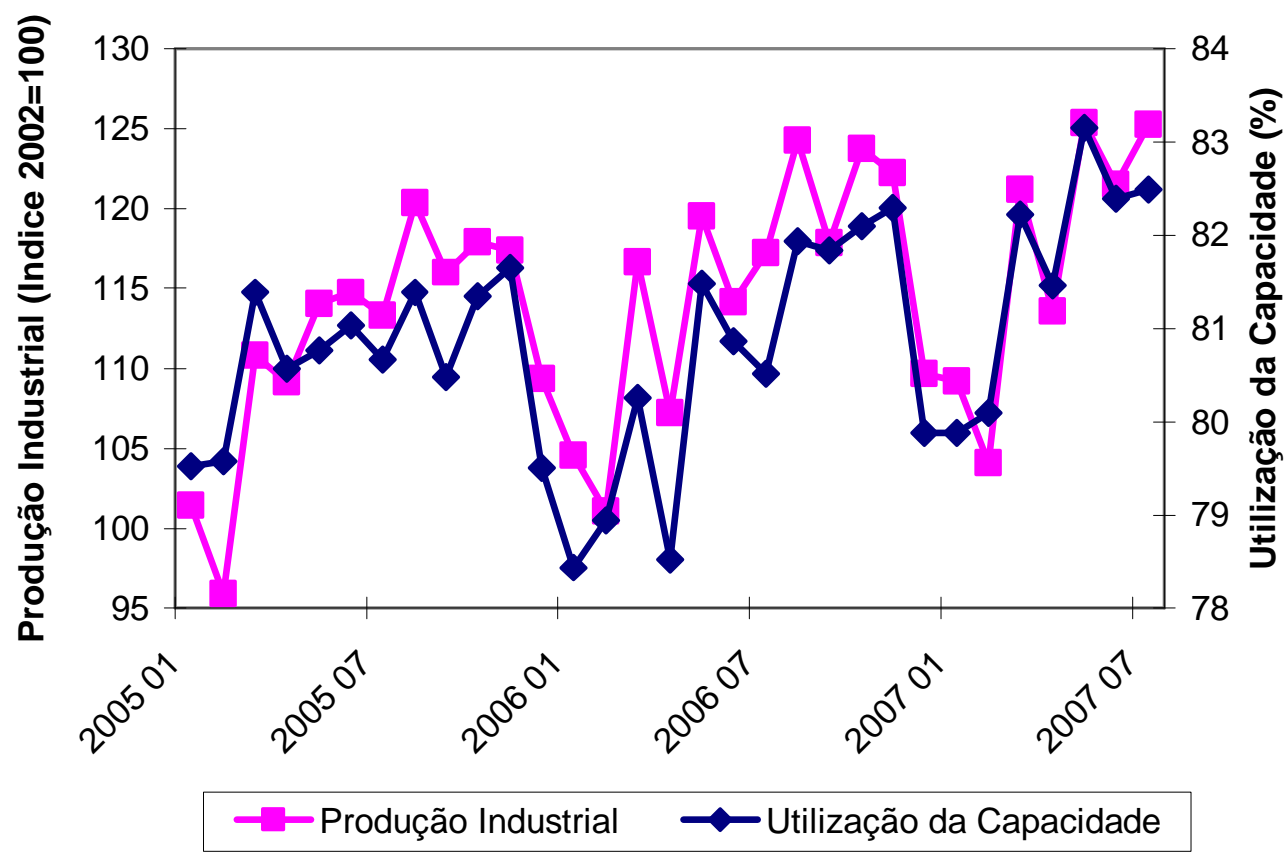

\section{Comércio Internacional}

O desempenho das principais variáveis do setor externo é apresentado na tabela 5. Em agosto de 2007 o saldo da balança comercial ficou em US \$3,53 bilhões, acumulando no ano de 2007 um valor de US $\$ 27,49$ bilhões. As exportações e as importações já acumulam, no ano, um valor de US\$ 102,38 bilhões e US\$ 74,89 bilhões, respectivamente. Em doze meses, a balança comercial apresentou um superávit de US\$ 44,04 bilhões, as exportações um valor de US \$151,69 bilhões e as importações US \$ 107,65 bilhões. O saldo em transações correntes, em julho, apresentou um superávit acumulado em 2007 de US\$3,66 bilhões.

As expectativas de mercado para dezembro de 2007 mostram que se espera uma redução no saldo da balança comercial em relação aos números acumulados nos últimos 12 meses, indicando uma elevação maior nas importações do que nas exportações, conforme destacado na tabela 5. Para o ano de 2008 o mercado espera uma redução ainda maior do saldo da balança comercial, indicando um forte aumento das importações. Dessa forma, espera-se também para 2008, segundo a Gerin, uma redução substancial no saldo em transações correntes.

As variáveis externas indicam um forte fluxo de comércio (exportação e importação) e uma entrada líquida de dólares, pelo saldo em transações correntes, considerando-se o resultado acumulado em 2007. 
A taxa de câmbio apreciada é conseqüência do forte resultado do setor externo, tanto pelo saldo da balança comercial como pela entrada de capitais. Mesmo com a ocorrência da denominada "crise imobiliária" norte-americana, a taxa de câmbio permanece apreciada e após algumas semanas de volatilidade parece estar voltando ao patamar "pré-crise". Contudo, a queda significativa na taxa de câmbio nominal e real prejudica as atividades produtivas, voltadas direta ou indiretamente para as exportações. O Gráfico 3 apresenta a evolução das taxas de câmbio real e nominal no Brasil.

Tabela 5. Desempenho dos principais indicadores externos

\begin{tabular}{lccccc}
\hline \multicolumn{1}{c}{ Setor externo (us\$ milhões) } & $\begin{array}{c}\text { Agosto } \\
\text { de 2007 }\end{array}$ & $\begin{array}{c}\text { Acumulado } \\
\text { em 2007 }\end{array}$ & $\begin{array}{c}\text { Acumulado } \\
\text { em 12 meses }\end{array}$ & $\begin{array}{c}\text { Expectativa } \\
\text { para 2007 }\end{array}$ & $\begin{array}{c}\text { Expectativa } \\
\text { para 2008 }\end{array}$ \\
\hline Balança comercial & 3.535 & 27.498 & 44.046 & 42.650 & 36.070 \\
Exportações & 15.101 & 102.388 & 151.695 & 155.350 & 165.450 \\
Importações & 11.566 & 74.890 & 107.649 & 112.700 & 129.380 \\
Saldo em transações correntes* & -717 & 3.666 & 11.469 & 10.740 & 3.950 \\
\hline Fonte: Banco Central do Brasil e Instituto de Pesquisa Econômica Aplicada (IPEADATA) &
\end{tabular}

\section{Gráfico 3. Taxas de câmbio nominal e real (1994=100)}

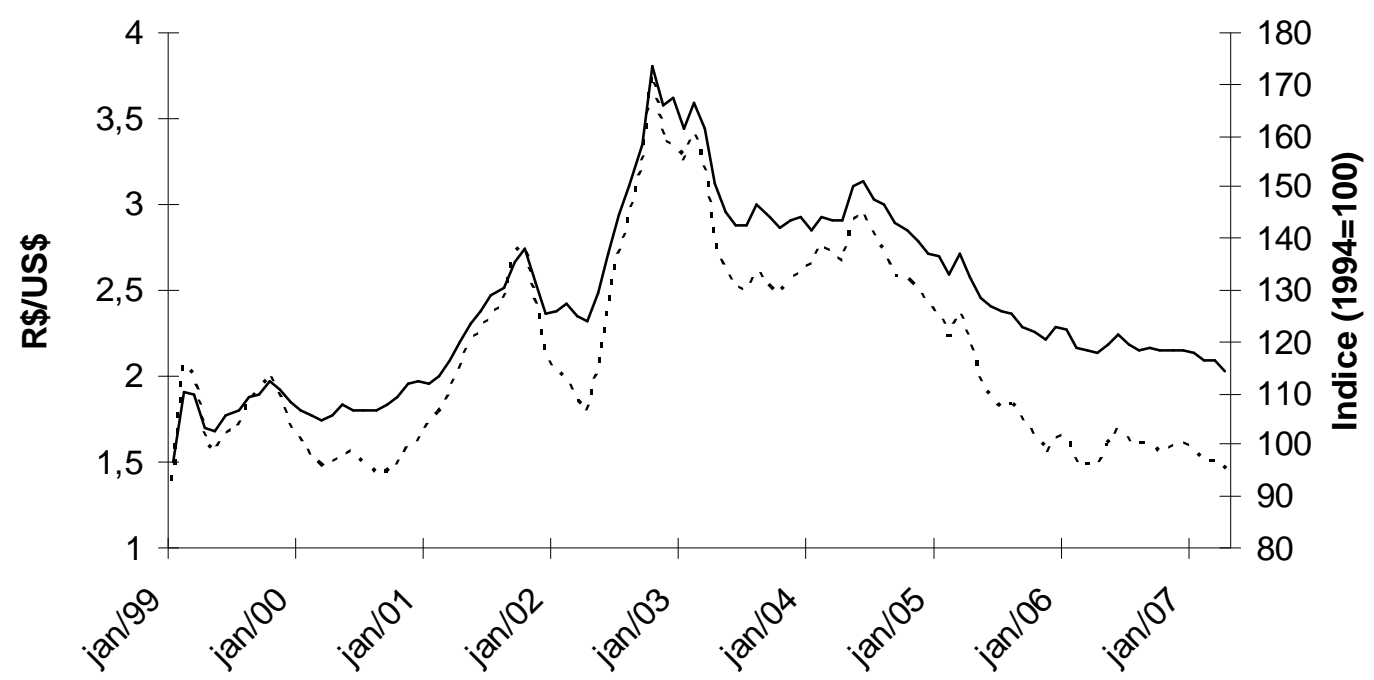

Câmbio Nominal ..... . Câmbio Real

Fonte: Banco Central do Brasil

\section{Mercado de Trabalho}

A taxa de desemprego nas principais regiões metropolitanas, registrada em junho de 2007, foi de 9,7\% da PEA. Considerando julho de 2007 em relação ao mesmo período do ano anterior, a taxa ficou significativamente menor, em 9,5\% em comparação com 10,7\% da PEA 
(gráfico 4). O rendimento médio real vem apresentando uma grande recuperação. No setor privado, o salário passou de $\mathrm{R} \$ 992,00$ para $\mathrm{R} \$ 1.010,00$, num período de julho de 2006 a 2007, crescimento real de 18,15\%. Considerando o setor público, onde os salários são maiores, o rendimento médio passou de $\mathrm{R} \$ 1.664,00$ para $\mathrm{R} \$ 1.708,00$, no mesmo período, com crescimento real de $26,44 \%$ (ver gráfico 5 ).

Gráfico 4. Taxa de desemprego nas principais regiões metropolitanas

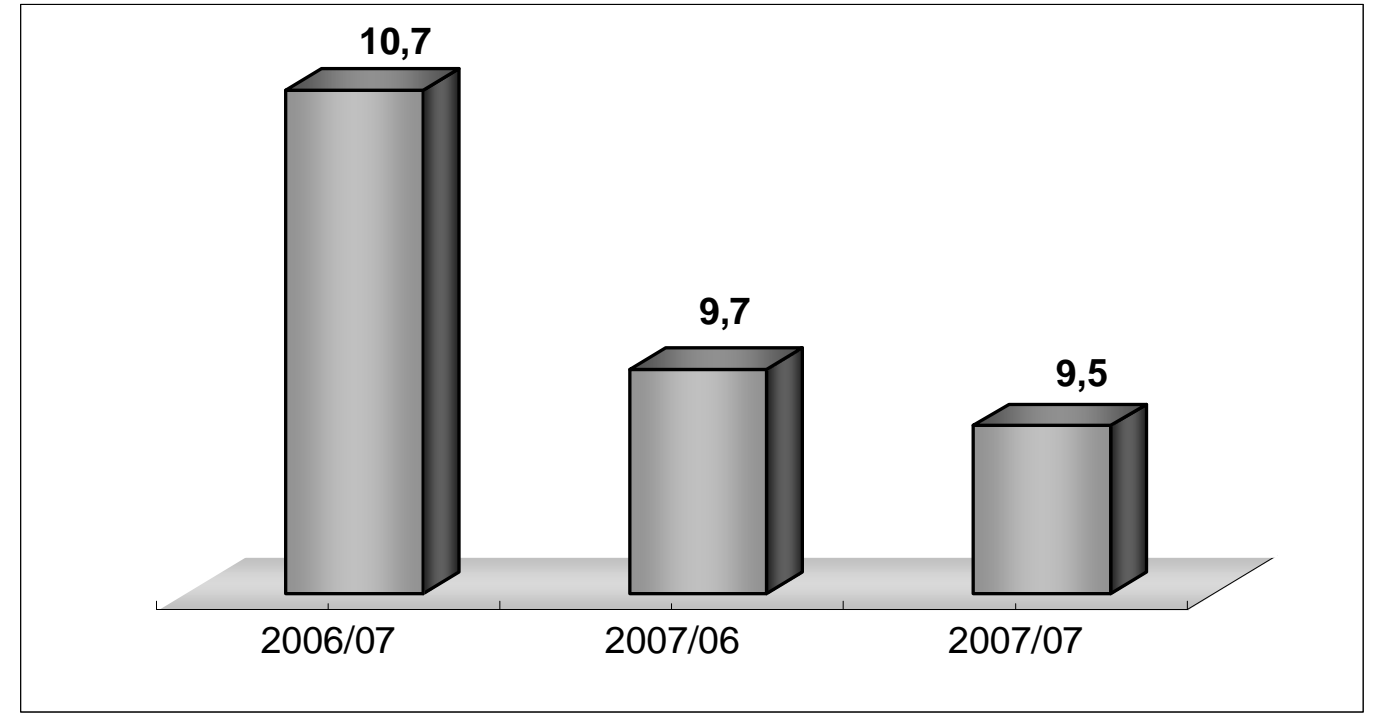

Fonte: IBGE. Região Metropolitana : RE, SAL, BH, RJ, SP E POA

Gráfico 5. Desempenho do salário médio real nas principais regiões metropolitanas, no setor privado e no setor público

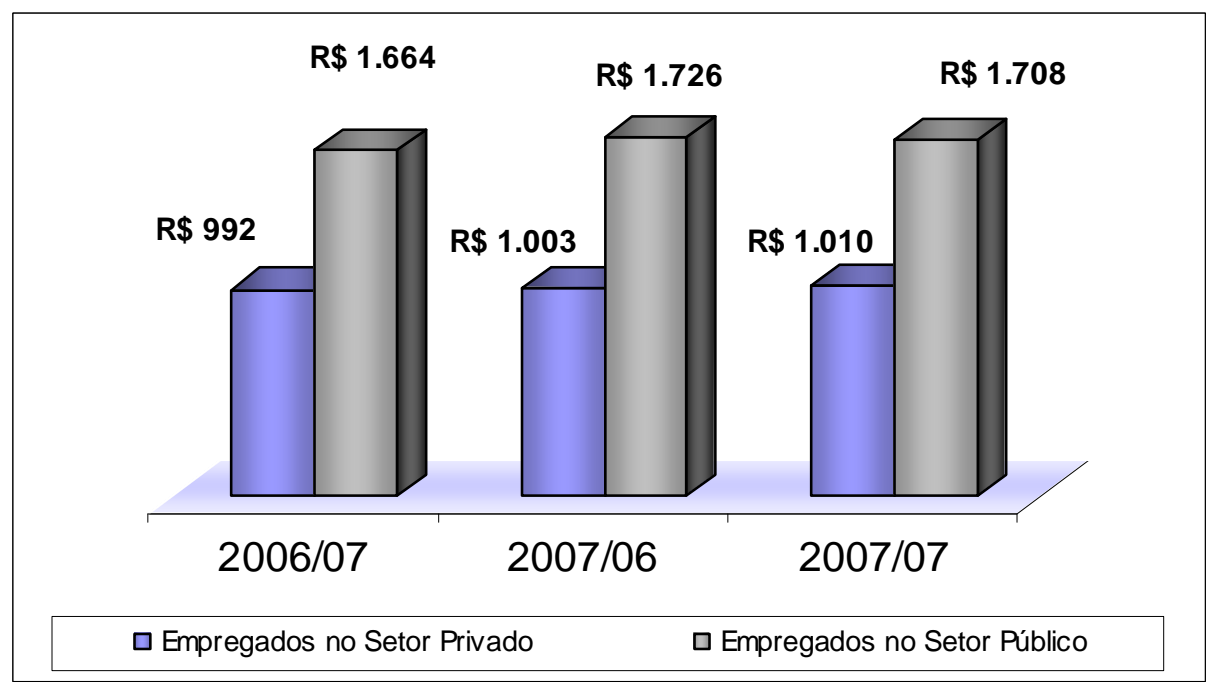

Fonte: IBGE. Região Metropolitana : RE, SAL, BH, RJ, SP E POA 


\section{Política Monetária}

A taxa de juros praticada na economia brasileira em setembro de 2007 foi de $11,25 \%$, abaixo do valor registrado de $11,50 \%$ no mês anterior. Com uma inflação acumulada em 12 meses pelo IPCA de 4,18\% (ver tabela 1), calcula-se uma taxa de juros real de 6,79\% ao ano. Projetando a taxa de juros real para o final do ano de 2007, pode-se argumentar que com a taxa de juros nominal esperada de $10,93 \%$ ao ano e esperando uma inflação do IPCA de $3,94 \%$, a taxa de juros reais estaria em $6,73 \%$. Fazendo o mesmo exercício, temos uma queda gradual e consistente da taxa de juros reais da economia brasileira, como demonstrado na tabela 6 .

Por exemplo, em 2011, de acordo com o Banco Central (Gerin), o mercado espera uma taxa de juros nominal em torno de $8,73 \%$. Como a inflação esperada para o final desse ano é de 3,95\% (ver tabela 2), a taxa de juros esperada (forward looking) é de 4,60\% ao ano.

Tabela 6. Taxa de juros (\%), câmbio (R\$/US\$) e Expectativas

\begin{tabular}{lcccccc}
\hline & \multicolumn{5}{c}{ Expectativas } \\
\cline { 2 - 7 } \multicolumn{1}{c}{ Descrição } & $\begin{array}{c}\text { setembro } \\
\text { de } 2007\end{array}$ & 2007 & 2008 & 2009 & 2010 & 2011 \\
\hline Taxa de juros Selic & $11,25 \%$ & $10,93 \%$ & $10,13 \%$ & $9,43 \%$ & $9,05 \%$ & $8,73 \%$ \\
Taxa de juros reais & $6,79 \%$ & $6,73 \%$ & $5,87 \%$ & $5,20 \%$ & $4,87 \%$ & $4,60 \%$ \\
Taxa de câmbio nominal (R\$/US\$) & 1,91 & 1,90 & 1,95 & 2,04 & 2,09 & 2,14 \\
\hline
\end{tabular}

Fonte : Banco Central do Brasil. Boletim Economia \& Tecnologia

Com relação à taxa de câmbio nominal, o mercado espera uma certa estabilidade para os anos de 2007 e 2008. Os ajustes nominais esperados do câmbio no longo prazo são irrelevantes para o equilíbrio do setor externo.

A condução da política monetária (leia-se: determinação da taxa de juros Selic) tem como objetivo principal no Brasil manter a estabilidade dos preços, determinada pelo IPCA. O regime de metas de inflação leva em consideração o desempenho de vários indicadores, variáveis e mercados e suas influências sobre os preços na economia. Neste sentido, podemse destacar os seguintes pontos:

i. As expectativas de inflação para 2007 estão em 3,94\%, isto é, ancoradas com a meta de 4,5\% do IPCA com +/- 2 pontos percentuais;

ii. Os principais índices de preços estão apresentando um comportamento de convergência em suas variações anualizadas, com tendência de elevação;

iii. A expectativa do mercado para o crescimento do PIB em 2007 está em 4,73\%; 
iv. O setor da economia que apresenta maior expectativa de crescimento, tanto em 2007 quanto em 2008, é a agropecuária;

v. Os saldos da balança comercial e de serviços, atual e o esperado para o fim do ano, ainda são expressivos, porém as expectativas são de redução do saldo comercial para 2008;

vi. A taxa de juros real em setembro está em $6,79 \%$ ao ano, valor que pode levar a economia em um crescimento acima do seu potencial.

Gráfico 6. Taxa de Juros (Selic) - julho de 2005 a setembro de 2007

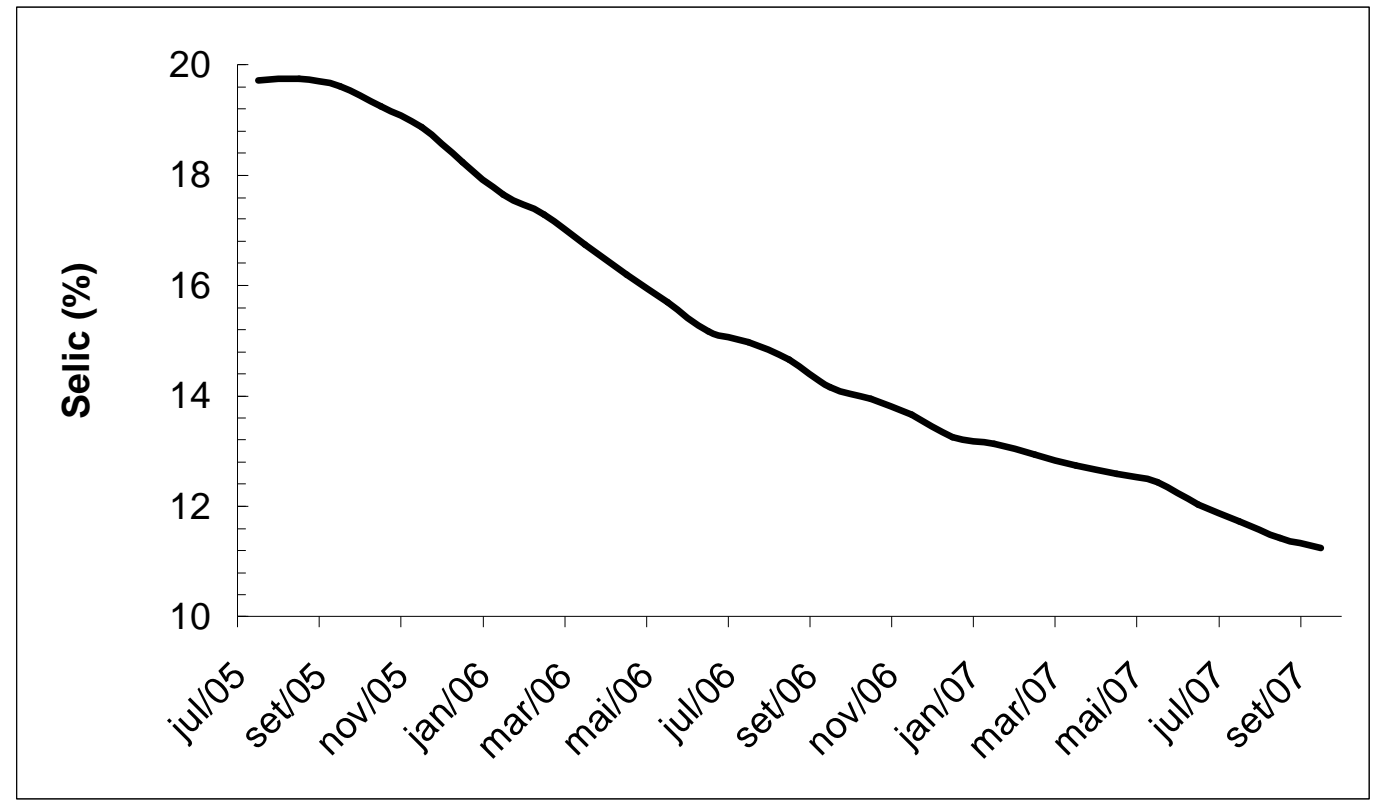

Fonte: Banco Central do Brasil

Com os resultados expostos acima, pode argumentar-se que a inflação e a análise de crescimento da oferta e da demanda devem ser bem monitoradas. Caso não se observem pressões significativas no nível geral de preços da economia, a taxa de juros pode continuar caindo a um ritmo de $0,25 \%$. 


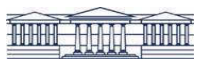

UFPR 